\title{
Discussion on Continuous Improvement of Blended Learning of Fundamentals of Circuit Analysis Course
}

\author{
Wei Huang, Caili Gong, Huijuan Wu, Junlin Wang, Kai Sun, Zhi Weng* \\ College of Electronic Information Engineering, Inner Mongolia University, Huhhot, China \\ Email: *wzhi@imu.edu.cn
}

How to cite this paper: Huang, W., Gong, C. L., Wu, H. J., Wang, J. L., Sun, K., \& Weng, Z. (2021). Discussion on Continuous Improvement of Blended Learning of Fundamentals of Circuit Analysis Course. Creative Education, 12, 2328-2334. https://doi.org/10.4236/ce.2021.1210176

Received: September 19, 2021

Accepted: October 16, 2021

Published: October 19, 2021

Copyright $\odot 2021$ by author(s) and Scientific Research Publishing Inc. This work is licensed under the Creative Commons Attribution International License (CC BY 4.0).

http://creativecommons.org/licenses/by/4.0/

\begin{abstract}
The reform of any course cannot be accomplished in one move and needs to be improved continuously for a long time. The scheme of blended learning reforms was shown from selecting online learning resources, dividing curriculum content, the problem of Blending learning hours and the implementation of discussion and cooperative learning in this paper. We also discussed some problems faced by Fundamentals of Circuit Analysis course in the Blending learning reform, and shared some of the accumulated experience and relevant suggestions. After 4 years' blended learning reforms, the class based on Fundamentals of Circuit Analysis has effectively improved the dull state, and enhanced students' interest in learning, which has also significantly improved the teaching effect. At the same time, this "student-centered" teaching design plays a great role in cultivating students' innovation ability.
\end{abstract}

\section{Keywords}

Blended Learning, Online Resources, Offline Learning, Discussion Class, Innovation Ability

\section{Introduction}

To improve the level and quality of higher education in China, the Ministry of Education launched the First-Class Courses construction project in 2019. It requires innovative teaching content, highlighting the cultivation of students' ability and quality, making full use of information-based teaching methods to innovate teaching mode and strengthening the teaching assessment to improve the challenge of learning. At present, blended learning is a hot topic in higher education. With the popularization of online open courses and other resources re- 
presented by MOOC, high-quality education resources gradually become less scarce, which makes the competition of higher education entering a more substantial classroom teaching competition. Most one-way imparting knowledge modes as the main feature are not the ideal classroom in the mind of teachers. Changes of the external environment and the pursuit of ideal classroom are the driving forces for teachers to carry out teaching mode reform (Yu, 2019). Therefore, blended learning has become a new trend of teaching development.

The Fundamentals of Circuit Analysis is a professional basic course for electronic information students, which lays a necessary foundation for follow-up courses such as analog circuit, digital circuit. This course has a great impact on the whole curriculum system, so the teaching mode has always been highly valued by teachers and students. Since 2018, the course has been blended learning for 4 years. During this process, some problems were encountered, such as the selection of online resources, the division of curriculum content, the calculation of blended learning hours, the implementation of discussion and cooperative learning. At present, the curriculum is still in the process of continuous improvement.

\section{The Selection of Online Learning Resources}

The Fundamentals of Circuit Analysis is a compulsory course for all electronic information students, so it is widely offered by relevant majors in relevant colleges and universities. There are many mature MOOC (Massive Open Online Courses) resources on the Internet. Take China University MOOC as an example, the number of similar courses exceeds 30 (China University MOOC Website, n.d.). Among these courses, there are about 10 national excellent online open courses. It is a difficult to choose the online resources which are suitable for teaching in our university from the numerous excellent resources.

The scheme adopted by the early course team was to select video clips based on the syllabus, which was suitable for our teaching from a large number of courses. And the video clips were pushed to students before class for online learning using the information-based teaching means such as rain classroom. The advantage of this approach is that teachers need to watch a lot of online MOOCs of the same type during the course preparation, so that teachers can learn from each other to make up for their shortcoming and improve the teaching level. In addition, online resources were selected according to the teaching content of each section, which was most suitable for students. However, this approach also had great disadvantages, that is, there is no suitable platform to record students' online learning data, and it is impossible to control the quality of students' online learning.

The video resources name and address are pushed to students, who choose courses as social learners and study the corresponding chapters only. They have not completed all the course requirements, so there are no course grades and certificates. However, teachers do not have the right to check the platform, so it 
is impossible to control whether students complete online learning of videos and how the results are achieved. The way we control the quality of online learning is to rely on online testing. The test questions assigned by the teacher in the rain classroom must be completed after online learning. At the same time, the test questions must also be set to test the online learning achievements before the face-to-face classroom.

To solve this situation of "guerrilla" online learning in each lesson, the course team launched self-built MOOCs in 2020, and then chose self-built MOOCs for online learning. The advantage of this approach is that the syllabus together with explanations of key and difficult points of the self-built MOOCs is basically consistent with the requirements for students in our school. It is completely suitable for students to use this MOOCs for online learning in terms of content. What's more, self-built MOOCs provide a platform to manage students' online learning, which can do a comprehensive management for students' online learning.

Some problems are also found in the use of self-built MOOCs as online resources. Teachers are always reluctant to give up some excellent video clips on the Internet. Students may be inspired by short snippets of lectures given by famous teachers, and some inspiring examples that are different from those in self-built MOOCs need to be understood. All these have prompted us to adopt a comprehensive strategy in the choice of online teaching resources. Both self-built MOOCs or SPOC (Small Private Online Course) for a selected course and a small amount of additional teacher-approved video resources can be pushed in rain classroom, which is currently adopted.

As for the selection of online resources, it is necessary to integrate current highquality resources according to the teaching syllabus and keep pace with the times, so as to obtain better online learning effect.

\section{The Division of Teaching Content}

\subsection{Online and Offline}

The problem in blended learning cannot be avoided. It is one of the most important issues in blended learning for how to divide teaching content before, during and after class, and how to divide online and offline teaching content ( $\mathrm{Li}$, Zhang, Zheng, \& Wang 2016).

First of all, we arrange some basic concepts, simple examples and applications in online learning before face-to-face teaching. These concepts are not too difficult for students, and they can be fully mastered by video learning and viewing the pushed course materials. To control the effect of online teaching, we will assign several questions for students to answer in the SPOC class or the Rain Classroom after completing each online learning session. The questions should be directly related to the online learning content, and should not be selected to investigate the type of knowledge expansion and extension.

In addition, the teaching content of face-to-face class should be difficult to arrange the learning content which requires teachers and students to inspire, com- 
municate, discuss, or extend the basic concepts. Such teaching content is better in the form of face-to-face teaching, which is convenient to interact with students, and the content and form of classroom teaching can be timely adjusted according to students' response. In the blended learning, the time is relatively loose in class, which can be used to better maintain interaction with students, grasp students' understanding and mastery of knowledge in real time by using various forms such as setting questions, submitting papers and voting in the rain classroom.

The most basic process of teaching is face-to-face lecture, which is the most efficient teaching method. The key lies in the content and structure of the lecture, which is closely related to the logic and order of the lecture and the analysis of academic conditions (Zhong \& Feng, 2019). The lecture is not only the main implementation way of the most basic heuristic and guided-teaching methods, but also an indispensable basic link in the teaching methods such as discussion, case, problem, and project.

The pushed content after class is more an extension of some classroom content, with fewer videos. Some high-quality discussion questions can be pushed to expand students' thinking, or some relevant scientific papers can be pushed to lead students understanding the cutting-edge trends of scientific research (See \& Conry, 2014).

Different students have different expectations for Fundamentals of Circuit Analysis course. A good course should not only ensure the quality of the course and the results of learning, but also meet the different needs of students. It is difficult to come into effect in traditional classrooms, but blended learning is better in differentiated education.

\subsection{Addition and Subtraction of Class Hours}

There are two common approaches in blended teaching. One is that the total number of hours is unchanged. Due to the introduction of online learning, offline learning hours become less, which is subtraction; another method is that the offline class hours remain unchanged, and the online class hours belong to an extra increase. So, the total class hours increase, which is to do addition (Xiao, 2021). Our course adopts the additive model. Because the difficulty of blended teaching engineering courses is relatively high, teachers have always advocated that the students should pay more attention to pre-study before class and note repetition after class. Therefore, it often needs students to spend twice as much time on learning after class in order to ensure the learning effect, after 2-hour classroom teaching. In this context, we choose mixed teaching using additive model, while the introduction of online learning will not increase students' learning burden. Of course, the addition and subtraction of class hours need to be related to specific disciplines and courses, which cannot be generalized.

\section{Discussion Class and Cooperative Learning}

In teaching, teachers often emphasize the depth and breadth of learning. "Depth" 
requires not only know what it is but also how it comes. The focus of teaching is not to address the problems simply, but to analyze problems thoroughly. The more comprehensive and in-depth analysis of problems is, the clearer the methods and process of solving problems are, during which process the students can integrate theory with practice. "Breadth" requires that teachers not only understand teaching materials, but also figure out the reason why they choose them, as well as its structure, way of organization and the evolution of the its composition. "Breadth" and "depth" complement and reinforce each other.

\subsection{Discussion Class}

The establishment of discussion class is a good way to improve teaching quality. By discussion, students can analyze problems fully and deeply, but it's often difficult to implement in ordinary classes. Taking engineering course as an example, a portion of class time for discussion sessions must be set aside due to the tight schedule, which means many teachers have to give up part of the teaching content. If students conduct discussion classes in their spare time, their weekends are often occupied.

It can well solve the above problems in blended learning. After using online teaching to digest part of the teaching content, less teaching content can be properly arranged in the limited teaching hours, and the saved time can be utilized to discuss with students. The discussion topics are often divergent, extended and thought-provoking, or some expansion of technical relevance in the actual production and life problems (Wang et al., 2021). These problems are difficult for students who only rely on knowledge in books, but the blended course can provide much more resources and information than ordinary classes. Students can broaden their horizons and consider the problem more comprehensively in learning. Thus, it is naturally easier to get an interest in the topic of the discussion course, and more likely to have a collision of ideas in the discussion course, which helps to achieve desired teaching effect (Lee \& Rha, 2009).

\subsection{Cooperative Learning}

The time saved in blended learning can be carried out not only in discussion classes, but also in cooperative learning. In the teaching of Fundamentals of Circuit Analysis, it is commonly found that freshmen do not know much about the industry background and the development trend of the professional field, which will have a negative impact on students' subsequent learning and future career planning. Therefore, in the teaching of some chapters, the teacher assigns cooperative learning tasks in advance, and the designated group completes the research, collation of materials and presentation. It is expected that the students can take the initiative to understand and master the corresponding knowledge in this link. For example, when we went to the operational amplifier part of our curriculum, it was the first time that the course touched on the integrated chip. 
The teacher arranged the content of this cooperative learning in advance as integrated circuit chips. When they received the task, the group of students presented the development history, key technologies and the highest level in the current development of the integrated chips. Meanwhile, they also introduced the top ten enterprises that produced integrated chips in the world, and analyzed the main bottlenecks encountered in the development of integrated chips in China and how to overcome the difficulties. For students of this major, it is essential to have these industry backgrounds. And in the cooperative learning session, it is often more interesting and memorable for students to explain the relevant content than teachers.

\section{Conclusion}

The careful teaching designs are the premise of the effective application of teaching methods. It is necessary to consider every detail fully in the teaching process, strengthen executing process, control process targetedly and take into account possible accidents or emergencies. We must consider the rationality, feasibility, operability, and effectiveness of the method intimately, combined with teaching objectives, content, and learning.

At present, the construction of "Double First-Class" in our country is accelerating, and the reform of undergraduate education is developing rapidly. For the teaching of college teachers, they must have skilled discipline expertise, advanced teaching concepts and profound subject teaching knowledge (Lin, 2012). The research results and the latest research's dynamics in the field of education and teaching can not only expand the view of teachers' academic research in teaching, but also help teachers re-examine the purpose and goals of teaching designs, curriculum designs and learning designs with new perspectives. Only teachers can conduct "teaching and learning" academic research to grasp and understand the direction of education and teaching reform, the law of education, teaching and talents' growth, we can adapt to active reforms from passiveness, and conduct innovative practice boldly in teaching.

\section{Acknowledgements}

This work was financially supported by New Engineering Research and Practice Project of the Ministry of Education (No. E-ZDH20201607), the Industry-University Cooperation Collaborative Education Project of the Ministry of Education (No. 2021101049011, No. 201902262001), Inner Mongolia Autonomous Region's online high-quality course construction project "Foundation Circuit Analysis", Inner Mongolia Autonomous Region first-class undergraduate course "Foundation of Circuit Analysis", Inner Mongolia Autonomous Region Educational Science Research “Thirteenth Five-Year Plan” Project (No. NGJGH2020013, No. NGJGH2020012) and Inner Mongolia University General Education Courses "The Wonderful Electronic World" and "Mobile Communication Technologies and Networks". 


\section{Conflicts of Interest}

The authors declare no conflicts of interest regarding the publication of this paper.

\section{References}

China University MOOC Website (n.d.). https://www.icourse163.org/

Lee, H. J., \& Rha, I. (2009). Influence of Structure and Interaction on Student Achievement and Satisfaction in Web-Based Distance Learning. Journal of Educational Technology \& Society, 12, 372-382. https://www.learntechlib.org/p/74974

Li, G. A., Zhang, N., Zheng, H. R., \& Wang, J. Y. (2016). Research on the Practice of University Flipped Classroom Teaching Based on Informatization Teaching. China University Teaching, 11, 61-65.

Lin, L. (2012). Outstanding Engineers' Train for the world. Research in Higher Education of Engineer, 2, 1-15.

See, S., \& Conry, J. M. (2014). Flip My Class! A Faculty Development Demonstration of a Flipped Classroom. Currents in Pharmacy Teaching \& Learning, 6, 585-588. https://doi.org/10.1016/j.cptl.2014.03.003

Wang, Q. Y., Huang, X. F., Wang, Z. W., Xu, J. C., Liu, J., Zheng, X., Sun, J., \& Peng, K. M. (2021). Exploration of Teaching Mode of Seminar in Engineering Courses under the Background of New Engineering Courses. Journal of Chengdu Normal University, 7, 45-51.

Xiao, X. Y. (2021). Exploration and Practice of Online-Offline Blended Teaching in College English Courses. Open Access Library Journal, 8, 1-9. https://doi.org/10.4236/oalib.1107512

$\mathrm{Yu}, \mathrm{X}$. J. (2019). Discussion on the Six Relations of Blended Learning. China University Teaching, 5, 14-18.

Zhong, W., \& Feng, Y. J. (2019). The Research of Blended Learning Model of the "Apple Teacher" Program. Creative Education, 10, 1764-1776.

https://doi.org/10.4236/ce.2019.108126 